\section{EVALUATION OF PATIENT'S PERCEPTION AND HEALING, FOLLOWING CONVENTIONALAND PARALLELING TECHNIQUE OF FRENECTOMY USING SCALPEL AND OTHER MODALITY.}

\author{
${ }^{1}$ Ira Gupta, ${ }^{2}$ Saranik Sarkar, ${ }^{3}$ Rohit Gupta, ${ }^{4}$ Nidhi Gupta, \\ ${ }^{5}$ Janardhana Amaranath B. J., ${ }^{6}$ Mohd. Amir Khan \\ ${ }^{1-6}$ Department of Periodontics \& Oral Implantology, \\ Rama Dental College Hospital \& Research Centre, Kanpur, India.
}

\begin{abstract}
:
Background: Frenum that encroaches on the margin of the gingiva may interfere with plaque removal and can lead to gingival recession and midline diastema. Thus, to maintain proper oral hygiene and prevent gingival recession, frenectomy is done. Frenectomy can be accomplished by conventional frenectomy technique, which has certain disadvantages. To overcome those drawbacks, paralleling technique of frenectomy has been introduced. Both the techniques can be performed by using various treatment modalities.

Aim: The purpose of this clinical study was to compare the bleeding during surgery, post-operative wound healing and patient's perception towards the conventional frenectomy technique with scalpel, paralleling frenectomy technique with scalpel and paralleling technique with electrocautery.

Materials and method: A total of 30 subjects with gingival or papillary frenal attachment were selected and equally divided into three groups. Group 1 was treated by conventional technique with scalpel, Group 2 by paralleling technique with scalpel and Group 3 by paralleling technique with electrocautery. Various parameters such as bleeding during surgery, patient's perception towards the various techniques and post-operative wound healing were evaluated.

Results: The results showed that bleeding during surgery was minimum in group 3 as compared to other two groups. Patient's perception towards paralleling technique with scalpel, was found better than the other groups. At 7th day, though there was a difference in the healing but at 21 st day wound healing was almost similar in all the three groups.

Conclusion: Based on our findings and clinical outcome, paralleling technique with scalpel provided better patient's perception and an efficient and satisfactory option for frenectomy.
\end{abstract}

\section{Research} Article

\author{
Key words: \\ Electrocautery; Frenectomy; \\ Frenectomy technique; Scalpel \\ Source of support : Nil \\ Conflict of interest: None
}

INTRODUCTION: A frenum is a mucosal fold, consisting of connective tissue and muscle fibers and it connects the lips and the cheek to the alveolar mucosa, the gingiva and the underlying periosteum.[1] A frenum that is closely attached to the gingival margin would compromise the health of the gingiva either by not permitting proper placement of a toothbrush resulting in poor oral hygiene practice or by muscle pull, leading to opening of the gingival sulcus, eventually leading to gingival recession and midline diastema, which may be of high esthetic concern and sometimes leading to speech difficulties. The facial surface between the maxillary and mandibular central incisors along with canine and premolar areas are most prone to frenal problems.

Depending upon the extension of attachment of fibres, frena have been classified as:[2]

Mucosal: When the frenal fibers are attached up to mucogingival junction

Gingival: When fibers are inserted within attached gingiva Papillary: When fibers are extending into interdental papilla Papilla penetrating: When the frenal fibers cross the alveolar process and extends up to the palatine papilla. 
Among these, papillary and papilla penetrating frenal attachments are considered as pathological and they lead to loss of papilla, gingival recession, diastema, brushing difficulty, teeth malalignment, hindrance in oral hygiene maintenance and psychological disturbances to individuals. [3,4] The abnormal frenum can be treated by frenectomy or by frenotomy procedures. Surgical removal of the aberrant frenum is known as frenectomy that includes the removal of its attachment to the underlying bone; whereas, frenotomy is the incision and the repositioning of the frenal attachment.[5] Earlier, the conventional technique of frenectomy was followed. But, the conventional technique with scalpel has certain disadvantages, namely large rhomboidal wound area, where primary closure is not possible in the lower part and healing takes place by secondary intention.[6] To overcome those drawbacks, a new technique (paralleling technique) has been advocated for frenectomy procedure. Paralleling technique has certain advantages over conventional technique, such as primary closure is possible in wound area and the primary intention healing takes place. Like the conventional technique, this technique can also be performed by scalpel and other modalities like electrocautery, cryosurgery or laser.

Laser being an expensive gadget and not easily available in clinics and also not readily affordable by patients, the present study compares the patient's perception towards and the healing following frenectomy by the, 1 . conventional technique with scalpel, 2. paralleling technique with scalpel and 3. paralleling technique with electrocautery.

MATERIALS \& METHOD :

Study design: The patients were selected from the Outpatient Department of Periodontics and Oral Implantology, Rama Dental College - Hospital \& Research Centre, Kanpur, UttarPradesh. The subjects underwent frenectomy for periodontal or orthodontic reasons. The ethical clearance for the study was taken from the Ethical Committee and review board of Rama Dental College.

Thirty subjects selected with aberrant frenal attachment were equally divided into three groups i.e ten subjects in each group.

Group 1: frenectomy by conventional technique using scalpel (Archer 1961, Kruger 1964).

Group 2: frenectomy by paralleling technique using scalpel (Abullais SS, Dani N, Ningappa P et al 2016)

Group 3: frenectomy by paralleling technique using electrocautery.

All the procedures were carried out by a single operator.

\section{Inclusion criteria:}

- Subjects in the age range of 18 - 35 years with positive tension test

- Systemically healthy subjects

- Subjects with abnormal papillary or gingival labial frenum were included

-Subjects who were willing to come for surgery and follow up.

\section{Exclusion criteria:}

- Smokers and tobacco chewers

- Subjects on antibiotics or anti- inflammatory drugs in past 3 months

- Subjects with prosthetic heart valves and cardiac pacemakers

- Those with history of any gingival and/or periodontal surgical treatment in past 6 months

- Pregnant or lactating women or women taking oral contraceptive pills.

Detailed case history of the participating patients was recorded. Signed informed consent was taken from every subject prior to the start of the study. Basic non-surgical therapy was completed for all the subjects and oral hygiene instructions were given. Complete hemogram was advised for all the patients prior to the surgery.

The area was anesthetized with 2\% lignocaine (with 1:80,000 adrenaline) in all the subjects and they received treatment based on the group alloted to them.

\section{Conventional frenectomy technique with scalpel:}

The frenum was held with the mosquito haemostat to its full depth. With the No. 15 blade mounted on a Bard-Parker handle, an incision was made along the upper surface of the haemostat till the entire depth of the frenum extending into the vestibule. A similar incision was repeated on the undersurface of the haemostat so that the haemostat is detached along with the frenal tissue. Once this was achieved, a rhomboid area exposing the deeper connective tissue fibers was visible. Then, the deeper fibers were incised with fine scissors to detach them from underlying periosteum. In order to prevent, reattachment of fibers, periosteal scoring was done. Pressure pack was applied to control bleeding from operative site. [Fig.1]

\section{Paralleling frenectomy technique with scalpel:}

The frenum was retracted and two paralleling incisions were placed on the side of the ridge of the frenum with a number 11 blade mounted on a Bard-Parker handle. After initial incision, 
deep dissection of the muscle fibers was done to eliminate all the attachments. Incised frenum was removed by giving releasing incision on the apex and base of the frenum. [Fig.2]

\section{Paralleling frenectomy technique with electrocautery:} The BONART electrosurgery unit(Model: ART-E1, Taiwan) was utilized for the procedure. The cutting electrode was set with $6 \mathrm{RF} / 2 \mathrm{MHz}$ and power supply of $230 \pm 10 \% 50 \mathrm{~Hz}, 0.9 \mathrm{~A}$ $220 \mathrm{~V}$. Two parallel incisions were placed on the side of ridge of the frenum using the electrode. In order to prevent heat buildup and unwanted tissue destruction the electrode tip was used intermittently in a 'shaving' motion and kept moving followed by irrigation with the normal saline to allow for adequate tissue cooling. Then, deep dissection of muscle fibers was done to eliminate all the attachments. Incised frenum was removed and it was made free. Following electrosection, the unit was switched on to coagulation mode (COAG 1) and the heavy ball electrode (T9) was used to arrest any minor bleeding and achieve optimal hemostasis. [Fig.3]

The wounds in the patients of group 1 and 2 were sutured using a 3-0 silk suture. After surgery, the operative areas were covered with a periodontal dressing $\left(\mathrm{COE}-\mathrm{PAK}^{\mathrm{TM}}\right)$ in all the 3 groups and all the three groups received postoperative instructions and they were told to use an analgesic if needed. The sutures that were placed in group 1 and group 2 patients were removed after a week.

\section{Assessment of Clinical Prameters:}

Bleeding score was recorded on the day of surgery in all the 3 groups. Patient's perception based on pain, speech and any other functional complications were recorded using a visual analog scale (VAS) on the day of surgery and postoperatively on 3rd, 7th and 15th day. Wound healing was also checked in all the groups postoperatively on 7 th and 21 st day.

\section{Methods of Scoring:}

A single operator recorded severity of bleeding (1:No bleeding, 2:Mild bleeding, 3:Moderate bleeding, 4:Severe bleeding) during the procedure. The patients were asked to rate their personal perceptions based on pain, discomfort during speech, speaking difficulty and any other functional complication on a $10 \mathrm{~cm}$ horizontal visual analogue scale(VAS) by placing a vertical mark to assess position between the two endpoints. The score were between 0 to 10 in the visual analogue scale. The left endpoint was designated as "no discomfort", and the right endpoint was designated as "severe discomfort". A single operator recorded these scores postoperatively on $3 \mathrm{rd}, 7$ th and 15 th day.

Wound healing at day 7 th and 21 st was assessed using the criteria of Landry, Turnbull and Howley (1988)[7] as follows:

\begin{tabular}{|c|c|l|c|c|l|c|}
\hline Scoring & $\begin{array}{l}\text { Interpretati } \\
\text { on }\end{array}$ & $\begin{array}{l}\text { Tissue } \\
\text { color }\end{array}$ & $\begin{array}{l}\text { Bleeding } \\
\text { on } \\
\text { palpation }\end{array}$ & $\begin{array}{l}\text { Granulation } \\
\text { tissue }\end{array}$ & $\begin{array}{l}\text { Incision } \\
\text { margin }\end{array}$ & $\begin{array}{l}\text { Suppu } \\
\text { ration }\end{array}$ \\
\hline 1 & Very poor & $\begin{array}{l}=50 \% \text { of } \\
\text { red gingiva }\end{array}$ & yes & yes & $\begin{array}{l}\text { not epithelialized, } \\
\text { with loss of } \\
\text { epithelium beyond } \\
\text { incision margin }\end{array}$ & Yes \\
\hline 2 & Poor & $\begin{array}{l}=50 \% \text { of } \\
\text { red gingiva }\end{array}$ & yes & yes & $\begin{array}{l}\text { not epithelialized, } \\
\text { with } \\
\text { connective tissue }\end{array}$ & No \\
\hline 3 & Good & $\begin{array}{l}25-50 \% \text { of } \\
\text { red gingiva }\end{array}$ & no & no & $\begin{array}{l}\text { nonnective tissue } \\
\text { exposed }\end{array}$ & No \\
\hline 4 & Very good & $\begin{array}{l}<25 \% \text { of } \\
\text { red gingiva }\end{array}$ & no & no & $\begin{array}{l}\text { no connective tissue } \\
\text { exposed }\end{array}$ & No \\
\hline 5 & Excellent & $\begin{array}{l}\text { all tissue } \\
\text { pink }\end{array}$ & no & no & $\begin{array}{l}\text { no connective tissue } \\
\text { exposed }\end{array}$ & No \\
\hline
\end{tabular}

[**2 or more signs should be present]

\section{RESULTS:}

Results of the study are summarized in tables 1-3.

Table 1: Intergroup comparison of bleeding during surgery

\begin{tabular}{|l|l|l|l|l|l|}
\hline & $\begin{array}{l}\text { Conventional } \\
\text { scalpel }\end{array}$ & $\begin{array}{l}\text { Paralleling } \\
\text { with scalpel }\end{array}$ & $\begin{array}{l}\text { Paralleling } \\
\text { with } \\
\text { electrocautery }\end{array}$ & $\begin{array}{l}\text { ANOVA } \\
\text { Test } \\
\text { p-value }\end{array}$ & Tukey HSD Test \\
\hline $\begin{array}{l}\text { Bleeding } \\
\text { During } \\
\text { Surgery }\end{array}$ & $3.8 \pm 0.42$ & $2.9 \pm 0.32$ & $2 \pm 0$ & $<0.0001$ & $\begin{array}{l}\text { Gp1 vs Gp2 }<<0.01 \\
\text { Gp1 vs Gp3 p }<0.01 \\
\text { Gp2 vs Gp3 p }<0.01\end{array}$ \\
\hline
\end{tabular}

Table 2: Intergroup comparison of patient's perception towards various techniques and modalities on the day of surgery and postoperatively on $3 \mathrm{rd}$, 7 th and 15 th day

\begin{tabular}{|l|l|l|l|l|l|}
\hline & $\begin{array}{l}\text { Conventional } \\
\text { scalpel }\end{array}$ & $\begin{array}{l}\text { Paralleling } \\
\text { with scalpel }\end{array}$ & $\begin{array}{l}\text { Paralleling } \\
\text { with } \\
\text { electrocautery }\end{array}$ & $\begin{array}{l}\text { ANOVA } \\
\text { Test } \\
\text { p-value }\end{array}$ & Tukey HSD Test \\
\hline $\begin{array}{l}\text { On the day } \\
\text { of surgery }\end{array}$ & $8.5 \pm 0.8498$ & $6.2 \pm 0.9189$ & $4.4 \pm 0.6992$ & $<0.0001$ & $\begin{array}{l}\text { Gp1 vs Gp2 }<<0.01 \\
\text { Gp1 vs Gp3 p }<0.01 \\
\text { Gp2 vs Gp3 }<0.01\end{array}$ \\
\hline On 3rd day & $7.4 \pm 0.6992$ & $5.2 \pm 1.0328$ & $4.9 \pm 0.7379$ & $<0.0001$ & $\begin{array}{l}\text { Gp1 vs Gp2 p }<0.01 \\
\text { Gp1 vs Gp3 p }<0.01\end{array}$ \\
\hline On 7th day & $5.6 \pm 0.5164$ & $5.1 \pm 0.3162$ & $4.2 \pm 0.4216$ & $<0.0001$ & $\begin{array}{l}\text { Gp2 Gp3 non } \\
\text { significant }\end{array}$ \\
\hline On 15th day & $2.8 \pm 0.4216$ & $2.1 \pm 0.3162$ & $1.5 \pm 0.7071$ & $\begin{array}{l}\text { Gp1 Gp2 }<0.05 \\
\text { Gp1 vs3 } \mathrm{p}<0.01 \\
\text { Gp2 vs Gp3 }<<0.01\end{array}$ \\
\hline
\end{tabular}

Table 3: Intergroup comparison of wound healing following various techniques and modalities postoperatively on 7 th and 21 st day

\begin{tabular}{|l|l|l|l|l|l|}
\hline & $\begin{array}{l}\text { Conventional } \\
\text { scalpel }\end{array}$ & $\begin{array}{l}\text { Paralleling } \\
\text { with scalpel }\end{array}$ & $\begin{array}{l}\text { Paralleling } \\
\text { with } \\
\text { electrocautery }\end{array}$ & $\begin{array}{l}\text { ANOVA } \\
\text { Test } \\
\text { p-value }\end{array}$ & Tukey HSD Test \\
\hline 7th day & $2.7 \pm 0.483$ & $3.2 \pm 0.4216$ & $1.7 \pm 0.483$ & $<0.0001$ & $\begin{array}{l}\text { Gp1 vs Gp2 non - } \\
\text { significant }\end{array}$ \\
\hline 21st day & $3.4 \pm 0.5164$ & $3.9 \pm 0.5676$ & $3.7 \pm 0.6749$ & 0.181348 & Gp1 vs Gp3 p $<0.01$ \\
\hline p-value & 0.009529 & 0.001328 & $<0.0001$ & & Gp2 vs Gp3 p $<0.01$ \\
\hline
\end{tabular}

DISCUSSION : In the modern era of periodontal plastic surgery, more conservative and precise techniques are practised to create better functional and esthetic results. Earlier, Archer's[8] and Kruger's[9] "classical techniques" of total frenectomy was followed to manage the aberrant frenum. Then, Edward's[10] more conservative approach came into picture. Recent techniques added frenal relocation by Z-plasty[11], frenectomy with soft-tissue graft[12,13] and laser[14,15] applications to avoid typical diamond-shaped scar and facilitate healing. Each method has its own advantages and disadvantages.

In conventional frenectomy procedure, frenum is held with a 
hemostat and two incisions are given, one is above and the another one is below the hemostat. This creates a large diamond shaped wound area with profuse bleeding. Patient often experience postsurgical bleeding and pain mainly because of the open area at the base of the frenectomy site, where primary closure is not possible because large part of mucosa has been removed. To overcome these problems, paralleling technique is used in the present study for frenectomy.

Primary closure is achievable throughout the length of the frenum in paralleling technique, because thin paralleling incision produces a close approximated margin.

Traditionally, the scalpel has been considered the surgical cutting tool of choice because of its precision, control, preservation of tissue integrity, and superior association with wound healing. Disadvantages are excessive bleeding, inadequate visibility caused by blood in the operating field and nonsterilizing incision cut.

The studies have shown that the advantages of electrocautery include coagulation and sealing of small diameter blood vessels resulting in blood free surgical field, clear view of the operative field and minimum postoperative scarring.[16] A reduction in postoperative pain is also achieved as a result of sealing of the free nerve endings and dendrites.[17] Hemostasis is immediate and consistent. Tip is selfdisinfecting.

Though lasers have marked the beginning of their use in soft tissue management, electrosurgery units are "far less expensive than the least expensive diode lasers" and hence it can be questioned whether "the advantages of the diode laser are significant enough to compensate for the additional cost".[18] Besides the cost aspect, the use of laser require more precision and control, as if the beam touches the bone surface it will cause necrosis of the bone. Also when David et al[19] compared mucosal incisions made by scalpel, CO2 Laser, electrocautery, he concluded that, on subjective evaluation of ease of use, constant-voltage electrosurgery scored highest $(\mathrm{p}<0.05)$ on a scale of 0 to 4 , followed by the $\mathrm{CO} 2$ laser. The speed of incisions and excisions, measured in seconds, was also faster for electrosurgery unit as compared to $\mathrm{CO} 2$ laser. The collateral tissue damage was also less in electrocautery group as compared to laser. Another advantage that electrocautery offers is that, there is no need for safety glasses and large amount of tissues can be removed quickly. Hence, use of electrocautery can be justified over the laser technique.

Only a few studies are available in literature those have compared the patient's perception and healing following frenectomy done by the conventional technique and paralleling technique using the scalpel or electrosurgery. $[20,21,22]$ Hence, this study was undertaken to evaluate patient's perception and to compare healing following conventional technique with scalpel, paralleling technique with scalpel and paralleling technique with electrocautery. In the present study, bleeding during surgery was maximum in conventional technique with scalpel followed by paralleling technique with scalpel and was minimum in paralleling technique with electrocautery. Thin parallel incision and less removal of gingival and mucosal tissues could be the reason for less bleeding in paralleling technique compared to conventional technique. The electrocautery procedure offered the advantage of almost bloodless field during the surgical procedure compared to scalpel. Intraoperative bleeding was minimum in the paralleling technique with electrocautery, probably, because of complete sealing off the blood vessels and faster clot formation in the operative site. Abullais S S et al[21] compared the paralleling technique of frenectomy with the conventional technique and they noticed less intraoperative bleeding in those patients who had undergone paralleling technique of frenectomy. Similar to the present study, intraoperative bleeding was minimum with electrocautery as compared to the scalpel in a study conducted by Bhullar A et al[20], where they have done a comparison between the conventional frenectomy with scalpel and with electrocautery.

While comparing the patient's perception, on the day of surgery it was observed that the patients who were treated by paralleling technique with electrocautery were the most comfortable one followed by the patients treated by the same technique but with scalpel and the patients who were treated by the conventional technique were the least comfortable. This is mainly because of the open area at the base of the frenectomy site by conventional technique, where primary closure is not possible because large part of mucosa has been removed.

On 3rd postoperative day, $80 \%$ patients of the paralleling technique with electrocautery group showed similar perception to the patients of paralleling technique with scalpel group, though, 2 patients complained of postoperative swelling in the paralleling technique with electrocautery group. Presence of postoperative swelling with electrocautery was also reported in the study conducted by Gandhi D et a[15] to compare the healing period after frenectomy using different modalities. 
Postoperatively, on 7th and 15th day, the patient's perceptions were much better for the paralleling technique with electrocautery group compared to the conventional group and the paralleling technique with scalpel group. Patients of paralleling technique with electrocautery group showed better perception due to the absence of bigger raw wound and pull by the sutures. Also, it is hypothesized that decreased pain perception and less functional complication after the use of electrocautery is due to the protein coagulum formed over the wound which acts like a biological dressing and aids in the sealing of nerve endings[23]. On the contrary, with the use of scalpel there is relatively more loss of blood, wider wound and use of sutures. Sutures also contribute to post operative discomfort since, they interfere with daily functions like speech and mastication[23,24]. Kapoor S et al, 2018[25] conducted a study to compare the patient's perception and degree of wound healing after frenectomy procedure with the various modalities and found the results similar to the present study.

In the present study, postoperatively on 7th day the patients treated with paralleling technique with electrocautery showed poor healing compared to conventional technique and paralleling technique with scalpel whereas, the healing were almost similar for all the 3 groups on 21 st day. Wound healing was faster in the paralleling technique with scalpel group because of the smaller size of wound, primary closure was there throughout the length of the frenum and close approximation of margin produced by thin paralleling incision. Though, the similar characteristics were found in the paralleling technique with electrocautery group, the damage around the incision line by the lateral heat would have made the healing slower as compared to the paralleling technique with the scalpel group.[16] Lateral heat damage is the area of coagulation necrosis produced around the incision line due to the unwanted heat production. The literature also suggests delay in healing when electrocautery is used. Kapoor $\mathrm{S}$ et al, 2018[25] and Gandhi D et al, 2017[5] reported delayed healing with electrocautery in their study during comparison of three treatment modalities i.e scalpel, electrocautery and laser for frenectomy procedure.

There was not much difference in the wound healing postoperatively on 7 th and 21 st day in the conventional group and paralleling technique with scalpel group. But, significant difference in wound healing was noticed in the paralleling technique with electrocautery group on 7 th and 21 st day. So, it can be said that the wound created by electrocautery takes more time for epithelization than scalpel.

\section{CONCLUSION :}

According to the present clinical study, all 3 methods can be used to treat aberrant frenal attachments but there are pros and cons for each one of them.

As, with conventional technique with scalpel, there was more intra-operative bleeding and least patient comfort but faster healing compared to electrocautery. The paralleling frenectomy technique with scalpel proved to be a better alternative to the conventional frenectomy technique in terms of minimal removal of tissue and lesser postoperative complications. Paralleling technique with electrocautery had shorter duration of surgery, minimal bleeding and discomfort; whereas, postoperative complication was seen in the two patients as a postoperative swelling. Though, patient acceptance was high for this technique but it had shown delayed healing than the scalpel.

So, on the basis of the present study, it can be concluded that among these 3 techniques, paralleling technique with scalpel is the preferable one for treatment of aberrant frenum.

However, there is a need for further studies with larger sample size and subjects who have multiple frenums to eliminate the confounding bias and to evaluate the clinical outcomes and postoperative functional satisfaction levels of patients after conventional and paralleling frenectomy technique using scalpel and other modality such as electrocautery, in order to reach to some final conclusion.

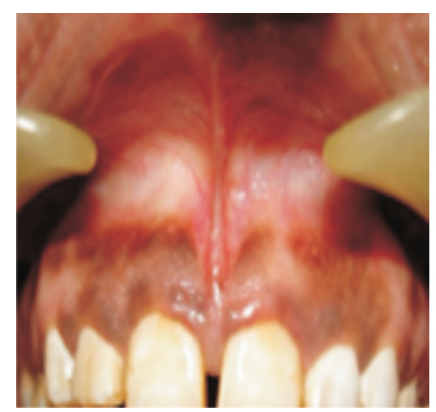

a. Pre-Operative

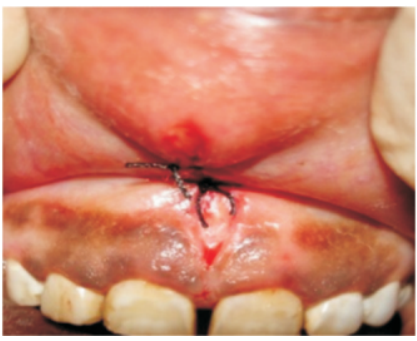

c. Suture Placed

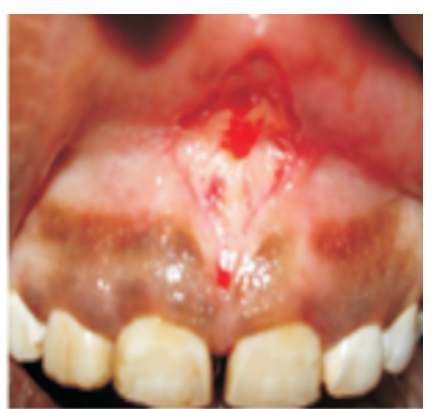

b. After Incision

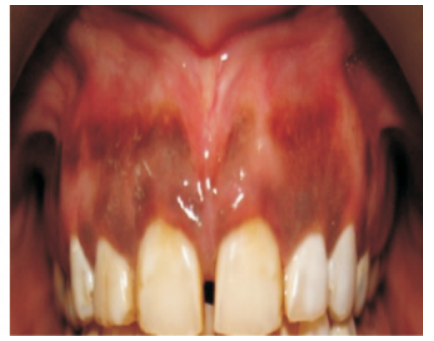

d. Post-Operative (21st day)
Figure: 1 Conventional frenectomy technique with scalpel 


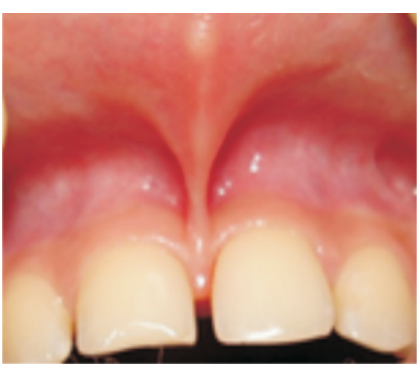

a. Pre-Operative

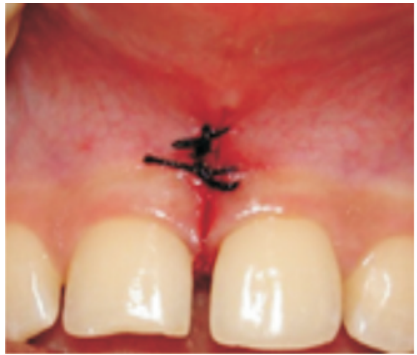

c. Suture Placed

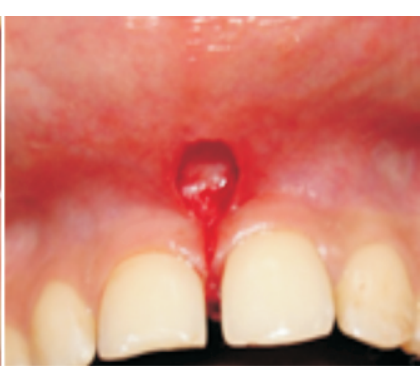

b. After Incision

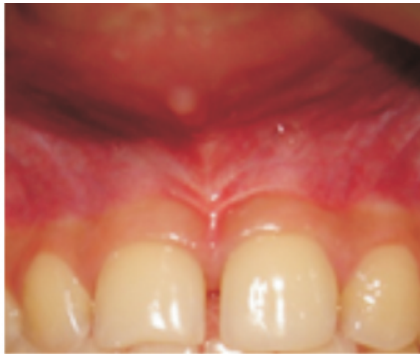

d. Post-Operative (21st day)

Figure:2 Paralleling frenectomy technique with scalpel

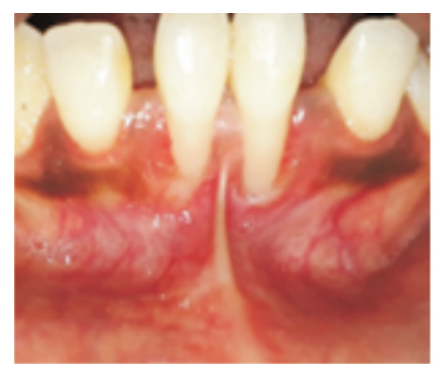

a. Pre-Operative

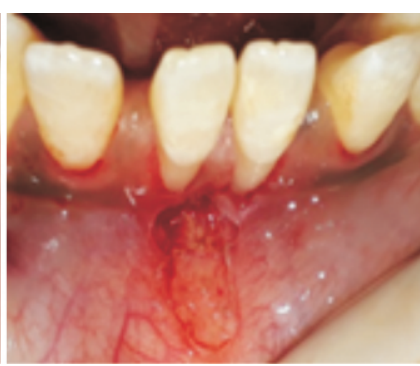

b. After Incision

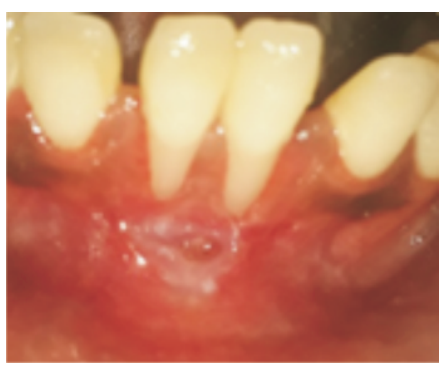

c. Post Operative (21st day)

Figure:3 Paralleling frenectomy technique with electrocautery

\section{REFERENCES :}

1. Takei HH, Azzi RA. Periodontal plastic and esthetic surgery. In: Newman MG, Carranza FA, editors. Carranza's Clinical Periodontology. London: W.B. Saunders; 2002. P. 870-71.
2. Taylor JE. Clinical observation relating to the normal and abnormal frenum labii superioris. Am J Orthod Oral Surg. 1939; 25:646-50.

3. Dewel BF. The labial frenum, midline diastema, and palatine papilla: A clinical analysis. Dent Clin North Am. 1966;10:175-84.

4. Diaz-Pizan ME, Lagravère MO, Villena R. Midline diastema and frenum morphology in the primary dentition. J Dent Child (Chic). 2006;73:11-4.

5. Gandhi D, Gandhi P. Comparison of Healing Period after Frenectomy Using Scalpel, Electrocautery \& Diode Laser. British Journal of Medicine \& Medical Research. 2017; 21(12):1-9.

6. Haytac MC, Ozcelik O. Evaluation of patient perceptions after frenectomy operations: A comparison of carbon dioxide laser and scalpel techniques. J Periodontol. 2006;77: 1815-19.

7. Landry RG, Turnbull RS, Howley T. Effectiveness of benzydamine $\mathrm{HCl}$ in the treatment of periodontal postsurgical patients. Res Clinic Forums. 1988;10:105-18.

8. Archer WH, editor. Oral Surgery - A Step by Step Atlas of Operative Techniques. 3rd ed. Philadelphia: WB Saunders Co.; 1961. P. 192.

9. Kruger GO, editor. Oral Surgery. 2nd ed. St. Louis: The C.V. Mosby Co.; 1964. P. 146.

10. Edwards JG. The diastema, the frenum, the frenectomy: A clinical study. Am J Orthod. 1977;71:489-508.

11. Tait CH. Median frenum of upper lip and its influence on spacing of upper central incisor teeth. N Z Dent J. 1929;25:116.

12. Coleton SH. Mucogingival surgical procedures employed in re-establishing the integrity of the gingival unit (III). The frenectomy and the free mucosal graft. Quintessence Int Dent Dig. 1977;8:53-61.

13. Breault LG, Fowler EB, Moore EA, Murray DJ. The free gingival graft combined with the frenectomy: A clinical review. Gen Dent. 1999;47:514-8.

14. Coluzzi DJ. Fundamentals of dental lasers: Science and instruments. Dent Clin North Am. 2004;48:751-70.

15. Gontijo I, Navarro RS, Haypek P, Ciamponi AL, Haddad AE. The applications of diode and Er: YAG lasers in labial frenectomy in infant patients. J Dent Child (Chic). 2005;72:10-5.

16. Bhatsange A, Meshram EP, Waghamare A, Shiggaon L, Mehetre V, Shende A. A clinical and histological comparison of mucosal incisions produced by scalpel, electrocautery, and diode laser: A pilot study. J Dent Lasers. 2016;10:37-42. 
17. Filmar S, Jetha N, McComb P, Gomel V. A comparative histologic study on the healing process after tissue transection. I. Carbon dioxide laser and electrosurgery. Am J Obstet Gynecol. 1989;160(5):1068-72.

18. Glenn A van. The diode laser as an electrosurgery replacement. C.E. article electrosurgery. 2013:6-13.

19. Libbon J., Funkhouser W, Terris J. D., A Comparison of Mucosal Incisions Made by Scalpel, CO2 Laser, Electrocautery, and Constant- Voltage Electrocautery. Otolaryngol Head Neck Surg. 1997 Mar;116(3):379-85.

20. Bhullar A, Verma S, Bhullar SK. A comparison of Frenectomy using Electrocautery and Scalpel Techniques. International Journal of Research in Health and Allied Sciences. 2018 Jul-Aug;4(4):42-45.

21. Abullais S S, Dani N, Ningappa P, Golvankar K, Chavan A, Malgaonkar $\mathrm{N}$, et al. Paralleling technique for frenectomy and oral hygiene evaluation after frenectomy. Journal of Indian Society of Periodontology. 2016 Jan-Feb;20(1):28-31.

22. Kotha M, Rekha BM, Vinaya KR. Evaluation of healing following labial frenectomy: A comparison of scalpel, electrosurgery and diode laser techniques. International Journal of Scientific Research. 2018 Oct;7(10):42-45.

23. Patel RM, Varma S, Suragimath G, Abbayya K, Zope SA, Kale V. Comparison of labial frenectomy procedure with conventional surgical technique and diode laser. J Dent Lasers. 2015;9:94-9.

24. Butchibabu K, Koppolu P, Mishra A, Pandey R, Swapna LA, Uppada UK. Evaluation of patient perceptions after labial frenectomy procedure: A comparison of diode laser and scalpel techniques. Eur J Gen Dent. 2014;3:129-33.

25. Kapoor S, Vandana, Kaur S, Prashar P, Gupta J. Lasers and Electrocautery- Alternative Modalities for Conventional Frenectomy Techniques. JIDA. 2018 Sep;12(9):18-25.

\section{CORRESPONDING AUTHOR:}

\section{Dr. Ira Gupta}

Professor,

Rama Dental College Hospital \& Research Centre Kanpur 3A/206, Flat: 1-A, Ram Kutir Appartments,

Azad Nagar, Kanpur-208002

Email:driragupta@yahoo.co.in 